\title{
Perversão clean na cultura do consumo ${ }^{1}$
}

\section{Clean perversion in consumer culture}

\author{
JOSÉ LUIZ A IDAR PRA D ${ }^{a}$ \\ Pontifícia Universidade Católica de São Paulo, Programa de Pós-Graduação em Comunicação e Semiótica. \\ São Paulo - SP, Brasil
}

\section{RESUMO}

A cultura contemporânea é montagem perversa, na medida em que busca liberar o sujeito egoísta para o mundo do sensível e da pulsão. Durante o século XX, houve crescente liberação das pulsões, estabelecendo-se uma ligação entre o neurótico consumidor e o perverso puritano. Busca-se a perversão, mas permanecendo-se clean, exigindo, para tal, batidas musicais pulsionais e substâncias variadas com graus entre o neurótico consumidor pós-moderno e o perverso puritano. O resultado é a interiorização da lei de mercado a fim de buscar a satisfação das pulsões, desligando quando possível a função sujeito. Para entender as transformações da cultura comunicacional da cidade perversa, é preciso uma teoria psicanalítica das pulsões e das paixões.

Palavras-chave: Psicanálise, perversão, capitalismo comunicacional, cultura do consumo, pulsões

\begin{abstract}
Contemporary culture is a perverse assembly, as it seeks to liberate the selfish subject to the world of the sensitive and the drive. In the 20th century an increasing liberation of the drives occurred, connecting the neurotic consumer and the puritan perverse. The perversion is sought, but remaining clean, demanding strong musical beatings and varied substances varying between the postmodern neurotic consumer and the puritan perverse to this end. The result is a society in which everyone internalizes the law of the market to satisfy the drives, disconnecting the subject function. To understand the transformations of communication culture of the perverse city, a psychoanalytic theory of the drives and passions is necessary.
\end{abstract}

Keywords: Psychoanalysis, perversion, communicational capitalism, consumer culture, drives 


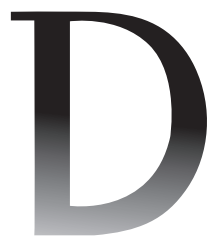

$\mathrm{N}$ OS ÚLTIMOS ANOS, tenho estudado os pontos sintomáticos do capitalismo comunicacional a partir de corpora variados (Cf. Prado, 2008, 2011, 2013, 2015a, 2015b, 2018; Prado \& Prates, 2017a, 2017b, 2019, Prado \& Cazeloto, 2017) dos media tradicionais e das redes sociais. No presente ensaio teórico, buscarei indagar como a atual cultura do consumo constrói a cena perversa, centrada numa atitude do perverso clean a partir da lógica neoliberal, que prega a capitalização do eu. Essa temática se conecta com as pesquisas anteriores, embora não examinemos aqui nenhum corpus específico, mas falemos de alguns objetos midiatizados exemplares: do esporte, da pornografia e da música, das raves, bem como aqueles ligados à judicialização cotidiana etc. Prosseguindo às pesquisas anteriores, trata-se, agora, de examinar a cultura do consumo do ponto de vista não somente das modalizações cognitivas (Cf. Prado, 2011), mas também a partir das lógicas afetivas de busca de gozo, ancoradas neste background perverso de sustentação cultural. Nessa direção, recorrer à psicanálise é um caminho fundamental, principalmente no que concerne ao desmentido e à porosidade atual em relação à perversão. Falar em imperativo do gozo na cultura atual do consumo implica em pensar o consumidor como um corpo sensível, identificado com figuras variadas afetivamente carregadas em busca do gozo. Em que falar de perversão clean nos ajuda a compreender essa cultura? Este será nosso caminho.

${ }^{2}$ Estamos usando gozo no sentido lacaniano, tradução de jouissance. Ele se refere à satisfação pulsional. Em $O$ Seminário, livro 20, Lacan (1985) opõe gozo ao útil, caracterizando-o como aquilo que não serve para nada. $\mathrm{O}$ dicionário de Chemama (1995) explica gozo como "diferentes relações com a satisfação que um sujeito desejante e falante pode esperar e experimentar, no uso de um objeto desejado" (p. 90).

\section{CULTURA DO CONSUMO E O NOVO SUPEREU}

A passagem da cultura de produção do capitalismo do início do século XX para a cultura do consumo do capitalismo comunicacional pós anos 1970, principalmente com o advento das redes digitais e do dinheiro eletrônico, deu-se com fortes transformações na sociedade e na formação psíquica do consumidor. Em linhas gerais, podemos dizer que o supereu freudiano declinou e deu lugar gradualmente ao supereu lacaniano que, ao invés de gritar o imperativo Isso é proibido, grita, com intensidade, enquanto faz vibrar o corpo do outro e o próprio: Seja um Eu S/A! Ganhe muito dinheiro! E goze cada vez mais! Alguns teóricos têm afirmado que os indivíduos de nossas sociedades, apesar de ainda neuróticos, buscam montagens perversas. Dardot e Laval (2016) ligam isso ao desenvolvimento do neoliberalismo, em que se erigiu um dispositivo de desempenho e gozo ${ }^{2}$. Neste texto, pretendemos situar de que se trata esse dispositivo e como dele depende o funcionamento comunicacional do capitalismo globalizado.

A cultura do consumo cresceu na medida em que produziu a figura do consumidor (Fontenelle, 2017), ensinando-o a consumir, libertando-o de algumas jaulas modernas e convocando-o para uma felicidade construída a partir da psicologia positiva (Freire Filho, 2010; Freire Filho \& Pinto Coelho, 2011). A subjetivação 
do consumidor é própria do liberalismo, sendo ele ideologicamente apresentado como racional, autônomo e com liberdade de escolha, mas de fato constituído por um corpo sensível, não podendo ser compreendido sem que acessemos uma teoria das paixões. Esse corpo pulsante, quando convocado, deve mergulhar na experiência, convidado a gozar. Nesta trajetória, a intensificação e a liberação das pulsões e do gozo apelaram cada vez mais ao sensível dos corpos. As convocações, desde os anos 1980, crescentemente interpelaram o consumidor neste nível sensível, para além da argumentação racional. Como dizem Dardot e Laval (2016), o neoliberalismo não impõe comportamentos, mas cria espaços para os sujeitos mergulharem de cabeça e entranhas num jogo de competição e desempenho: "o empreendedor de si deve sempre ganhar e ser bem sucedido" (p. 353). Neste jogo, há espetáculos exemplares para o aprendizado de tais processos. O esporte de competição é exemplar por constituir um grande teatro social adequado a esse capitalismo convocador, pois nele é apresentado, performativamente, um modelo de ação dos sujeitos. Um exemplo é a corrida Bravus (Pezzotti, 2018), na qual os participantes têm de superar uma série de obstáculos. As imagens mostram pessoas afundadas na lama, atravessando obstáculos difíceis, extenuadas, mas dirigidas por mandamentos que motivam a chegar ao final, a não temer os obstáculos, a enfrentar os medos etc. Há todo um conjunto de setores da economia voltado para o esporte, para as corridas, incluindo as academias, os suplementos alimentares, roupas específicas, gadgets para os esportistas se prepararem e acompanharem a corrida. Da mesma forma que há um mercado pornográfico.

Os reality shows são outro exemplo, com suas cruéis provas de resistência e paredões em que o público vai excluindo os competidores. Afirma Viana (2012, p. 45):

Seja mediante a paixão, o cálculo ou a paixão calculada, diante do "paredão" todos agem como se estivessem com uma arma apontada para a testa como se estivessem diante do fim.... A derrota não admite meios-tons, ela é absoluta, equivale à extinção. Segundo um participante da décima edição (do reality "A Fazenda"), "o paredão é que nem a morte" e estar no paredão é estar "jurado de morte". Em se tratando de fantasia ideológica, é o exagero que apresenta a efetividade; nesse caso, o exagero ficou aquém do fantasma do paredão. Pois a saída da casa é, ao mesmo tempo, a passagem para outra realidade e para nenhuma realidade. Trata-se de uma morte, mas de uma morte sem transcendência, pois do lado de lá do paredão está a aniquilação simbólica, o esquecimento.

Trata-se de um empreendedorismo para valer, em que falha é morte, esquecimento, derrota. As práticas sexuais também seguem as prescrições convocadoras desse modelo de empreendedorismo: 
${ }^{3}$ Julien (2003) relata o seguinte: W. Granoff faz, em 1956, a análise teórica de um caso de fetichismo, num artigo assinado com Lacan: "Trata-se de um menino de quatro anos, Harry, que A. Lorand encontra uma ou duas vezes por semana durante mais de seis meses. Ele costuma acariciar e beijar os sapatos das amigas de sua mãe. Pergunta se tal de suas amigas tem um grande 'peru' como seu pai, e desenha tanto as meninas como os meninos com um 'peru'.... W. Granoff responde: não se trata do pênis real, mas do falo no simbólico.

Com efeito, o fetiche deve

ser tomado como elemento

de uma atividade simbólica sem 'confusão entre a palavra

e seu referente.' A palavra torna presente o que está ausente.... O caso do pequeno Harry mostra claramente o que é a interpretação analítica: passar da relação a dois segundo o imaginário visual à relação pai-mãe-sujeito segundo a ordem simbólica da troca. Assim, a Verleugnung (denegação) é o sinal de uma oscilação mantida entre um e outro" (p.110).
As práticas sexuais, no imenso discurso "psicológico" que hoje as analisa, estimula e enche de conselhos de todos os tipos, tornam-se exercícios pelos quais cada um de nós é levado a confrontar-se com a norma do desempenho socialmente exigido: número e duração das relações, qualidade e intensidade dos orgasmos, variedade e atributos dos parceiros, número e tipos de posições, estimulação e conservação da libido em todas as idades tornam-se objeto de pesquisas detalhadas e recomendações precisas. (Viana, 2012, p. 353)

Para verificar isso, bastaria examinar as redes sociais e revistas impressas como a Nova (Cf. Prado, 2011, 2013). Mas o que isso tem a ver com a figura da perversão? Nos dicionários de psicanálise, a perversão está ligada a uma concepção normativa da sexualidade, ancorada na maturação trazida pela fase genital: perverso é quem, de alguma forma, precisa - para se satisfazer - desviar-se desse modelo genital normal. Isso ocorre talvez porque teria ficado fixado em fases anteriores, dominado por alguma pulsão parcial. Entretanto, nos dizem Laplanche e Pontalis (1992): "numerosas perversões como o fetichismo, a maior parte das formas da homossexualidade e mesmo o incesto realizado, supõem uma organização sob o primado da zona genital” (p. 342). Ora, isso complica a afirmação de que o perverso realiza um desvio em relação à norma genital.

Preferiremos o dicionário de Chemama (1995), que coloca a perversão como "uma fixação em um objeto imaginário em lugar da função fálica simbólica, que organiza o desejo por intermédio da castração e da falta" (p. 162). Ou seja, na perversão não se trata de um desvio simples de normas estabelecidas, mas de certo funcionamento do circuito pulsional em que o objeto é isolado em sua relação com o complexo de castração. Por exemplo, se a norma social afirma a sexualidade somente válida para a reprodução, trepar por prazer seria perversão, no uso comum do termo. Já na psicanálise, trata-se de algo mais complexo: no fetichismo, a perversão se mostra de modo particularmente exemplar ao acionar o funcionamento do desmentido. O perverso denega a castração feminina ao se deter no véu, no sapato, no brilho do tecido, ocultando que a mulher não tem o falo (simbólico). Em Lacan, não se trata de ter ou não ter o pênis, mas de estar "à altura do desejo da mãe" (Julien, 2003, p. 108), pois a criança se põe como objeto imaginário para preencher o desejo da mãe. Diz Julien (2003): “Ali onde nela [na mãe] o falo simbólico falta, o sujeito coloca no lugar um fetiche como falo imaginário" (p. 108) ${ }^{3}$. A rigor, dá-se a "instalação de um objeto de substituição metonímico em sua relação com a castração simbólica” (Chemama, 1995, p. 163). Assim, o perverso recusa a castração, mas se coloca no lugar da lei, buscando um gozo clandestino. Ele é um desmentidor, como diz Lebrun (2008, p. 345), pois renega a perda de gozo - a castração simbólica - implicada pela condição humana de seres da linguagem que somos. E o que isso tem a ver 
com as nossas sociedades atuais, com nossa cultura de consumo e seus laços sociais contemporâneos? Para esse autor:

O tipo de laço social organizado sobre o modelo patriarcal de ontem havia permitido que o sujeito - e igualmente a psicanálise - desconhecesse sua incidência fora do caso da perversão no sentido estrito. Hoje, com o fim do patriarcado, neurose e recalque tendem a perder sua prevalência e o mecanismo psíquico do desmentido, até então confinado na sombra, aparece em primeiro plano. . . . Se estamos sempre às voltas com neuróticos, eles não podem ser neuróticos “comuns” já que neles continua a prevalecer o desmentido. Nem por isso são perversos no sentido estrito. ... Mas são muito porosos à perversão, tendem a esposar-lhe a economia. (Lebrun, 2008, p. 345)

\section{DENEGAÇÃO}

Assim, o que ocorre na sociedade atual é a promoção de uma denegação da perda de gozo. Essa sociedade pós-patriarcado, dos movimentos sociais e do multiculturalismo, cuja lógica cultural é complementar ao funcionamento do neoliberalismo, ainda se compõe de neuróticos, embora sejam "muito porosos à perversão" (Lebrun, 2008, p. 346). Lebrun (2008) os chama de perversos comuns, no sentido de que não são os estritos perversos da época de Freud. Fixemos essa ideia de porosidade à perversão. O neurótico neoliberal é poroso em relação às montagens perversas. Aqui, estamos diante de uma mudança antropológica: a perversão hoje "não pode mais referir-se apenas à patologia médico-legal que nos fez reconhecê-la" (p. 346). Se o perverso comum percebe a perda, tapa-a com o véu, desmente-a. A cultura do consumo está aí para servir o consumidor com inúmeros objetos tamponadores, verdadeiras rolhas ou véus intransparentes. Tais objetos foram estudados em pesquisas anteriores (Cf. Prado, 2008, 2011, 2013, 2015a, 2018; Prado \& Prates, 2017a, 2017b, 2019) e aparecem não só nas revistas clássicas, mas também em blogs e sites dos influenciadores, que mostram e modalizam como ter sucesso, como ser o fodão, o primeiro, como chegar ao a mais. Esses objetos aparecem como fetiches, caminhos da plenitude gozosa. Como diz Julien (2003, p. 111), "o véu é a um só tempo o que esconde e o que designa”. Diante da possibilidade da perda, o sujeito poderia cair em desespero, a não ser que a cultura do consumo ofereça o objeto "livre de toda negatividade, proposto ao sujeito para permitir que ele não soçobre” (Lebrun, 2008, p. 346). Para Lebrun, "esse engodo, ao qual o sujeito vai poder se ligar, vai ajudá-lo sobretudo a perenizar a evitação do confronto com a perda” (p. 346). É, por assim dizer, uma saída, uma solução a partir de uma dispersão diante da perda. 
Dunker (2017, p. 229) define a perversão contemporânea como "o nome do que nos desperta indignação", o que sai do estado normal. Mas vimos que isso não basta, pois nem sempre a anomalia é o desvio ruim: "a anomalia que nega a norma pode ser um desvio progressivo, útil ou benéfico” (p. 229). Ele localiza três famílias da perversão:

a. A ligada ao traço de exagero ou à diminuição de algo que, na justa medida, seria tolerável ou desejável. "O perverso estereotipa um comportamento, fixa-se em um modo de estar com o outro e de orientar sua satisfação" (Dunker, 2017, p. 229). Exemplo: o sujeito que precisa que a mulher use um salto de dez centímetros e alisa-o ou lambe-o para poder gozar.

b. A ligada ao desvio: o perverso se desgarra dos outros e assume um lugar fora da ordem. Aqui, diz Dunker (2017), a negação da norma é afirmação de sua força. A ideia central é de "deslocamento, inversão e dissociação" (p. 230). O mais importante na empresa não é que o funcionário cumpra à risca as ordens, mas que leve a empresa ao pódio, ao lucro, aos objetivos do sistema.

c. A ligada à transgressão e violação da lei, a partir de uma identificação do sujeito com ela. Ele indica duas maneiras de perversão da lei: "afirmá-la por meio de uma negação ou negá-la por meio de sua afirmação" (Dunker, 2017, p. 230). Por exemplo, afirmo a lei, descumprindo-a.

Aqui, o autor toca num ponto importante: a perversão tem um caráter de fixidez e de desautorização da lei. Não se trata apenas de infração, pois é preciso considerar também o modo "como nos colocamos e situamos o outro, diante do que fazemos" (Dunker, 2017, p. 233). Dunker afirma que "não basta saber se o ato é conforme ou contrário à lei, mas que experiência ele produz em quem o realiza e o tipo de posição que ele confere ao outro" (p. 233). Haveria sim um supereu, mas ele estaria deslocado, "fora do sujeito, no seu infeliz e circunstancial parceiro" (p. 233).

Há vários exemplos de como o gozo, ou seja, o tipo de satisfação ordenado pelo supereu, constitui uma perversão particular e ao mesmo tempo um fator político incontornável. Há, por exemplo, um fascínio espontâneo por aquele que se coloca no lugar de supereu. A atração exercida por líderes e celebridades, assim como pelos 
sistemas totalitários, sejam eles nações, instituições, corporações ou mesmo empresas e grupos, baseia-se nesse sentimento de que eles expressam em exterioridade nossa própria relação perversa com a lei. Diante disso estaremos voluntariamente dispostos a servir como instrumento do gozo do outro, posto que ele é o meio pelo qual posso ter acesso deslocado à minha própria fantasia, exagerada pelo fato de ser vivida em massa. Isso tudo sem o ônus da culpa e do risco que estariam em jogo se eu me dispusesse a realizá-la por meios próprios. (Dunker, 2017, p. 233)

Dunker (2017) nos dá outros exemplos de como se dá a montagem perversa no concreto das atividades sociais, além daqueles que já abordamos:

Outro exemplo de montagem perversa são os sistemas e dispositivos burocráticos responsáveis pela judicialização da vida cotidiana. A burocracia é uma forma regrada e metódica de produzir anonimato e álibi para nosso desejo e, portanto, para confirmar a máxima perversa de que o outro deseja, mas segundo a lei que eu determino. Nessa medida há tanto perversão nos excessos alimentares - o bulímico e o anoréxico - quanto no discurso de vigilância sanitária sobre nossa alimentação, para não falar no exibicionismo de uma infância sexualizada pela moda, o voyerismo de nossos reality shows, a estética pornográfica de nossas produções culturais, o sadismo de nossos programas de violência ao vivo, o masoquismo do trabalho e da vida corporativa, o descompromisso líquido de nossa vida amorosa, a cultura de drogadição (legal e ilegal) e tantos fenômenos que costumam ser reunidos sob a hipótese de perversão generalizada. Ao contrário da perversão clássica, a perversão ordinária de nossos tempos é uma perversão flexível, silenciosa e pragmática. (pp. 234-235)

\section{LIBERAÇÃO DAS PULSÕES E MONTAGEM PERVERSA}

Moreira e Rosário (2012) falam não em sociedade perversa, mas em cena perversa, na qual domina, no campo social, a figura do narcisista. Haveria, nas sociedades narcisistas, um componente perverso, fazendo esmaecer a figura paterna e os laços sociais, promovendo um individualismo crescente em torno da cultura do consumo e dos ideais neoliberais do Eu S/A que se caracteriza, em nossos termos, por um investimento concentrado no automicroempreendimento, na capitalização do Eu.

Se pensarmos nessas questões a partir de uma articulação entre culpa e narcisismo na sociedade pós-moderna, diríamos, como Moreira e Rosário (2012), que houve um declínio da culpa em "sua vertente civilizatória, ou seja, aquela que promove o laço social como valor presente nas relações”, e corresponde na 
contemporaneidade "à configuração de uma relação social perversa e narcísica" (p. 74). Por outro lado, pode haver uma exacerbação do sentimento de culpa em relação ao próprio sujeito, criando uma báscula ligada à culpa:

Enquanto a ausência da culpa aponta para uma desconsideração da dimensão da alteridade, o seu excesso estaria ligado ao narcisismo primário, que tem como consequência o mesmo desvanecimento da alteridade. Assim, o sujeito é desculpabilizado na sua relação com o outro e culpabilizado na sua relação consigo mesmo por não responder a todos os signos de sucesso que elevam sua majestade - o eu à condição de eu ideal. (Moreira \& Rosário, 2012, p. 74)

As autoras concluem que o mundo pós-moderno reduz o campo da relação com a alteridade por duas vias: "ou o outro é reduzido porque ocorre uma diminuição da culpa do eu em relação ao outro, ou é diminuído porque vivemos uma exacerbação do eu ideal fechado em sua magnitude de rei" (Moreira \& Rosário, 2012, p. 74-75). Este tornar-se perverso do social refere-se, portanto, a uma redução do campo do outro. Em linhas gerais, o argumento freudiano de surgimento da cultura totêmica era ligado ao sentimento de culpa (o assassinato do pai da horda), o qual exigia a renúncia pulsional. Mas é preciso considerar que:

De início, a consciência é a causa da renúncia pulsional e, posteriormente, a relação se inverte. A renúncia torna-se uma fonte dinâmica de consciência e, a cada nova renúncia, aumenta a severidade e intolerância dessa última. Assim, a consciência é o resultado da renúncia pulsional e esta, por sua vez, cria a consciência que exige mais renúncias. (Moreira \& Rosário, 2012, p. 75)

Assim, nesta leitura, a montagem perversa da cultura de consumo pós-moderna se caracterizaria pela exacerbação do individualismo narcisista, pela consequente redução e negação do outro em sua radical alteridade (o outro é quem sequestra meu gozo), com a redução de projetos coletivos e a intensificação do investimento de cada um no gozo corporificado no outro, "sem densidade alteritária" (Moreira \& Rosário, 2012, p. 81). As lutas pelo reconhecimento seriam uma reação a esta tendência da cultura de consumo e à política individualizante neoliberal, bem como à concentração do projeto moderno na oposição entre capital e trabalho. Por outro lado, a recente e intensa resposta das extremas direitas seria a reação à culpabilização evocada por tais movimentos de reconhecimento. As autoras sintetizam este mal-estar da pós-modernidade: 
Dufour assevera que, na pós-modernidade, não estamos mais lidando com o sujeito neurótico caracterizado por uma culpabilidade compulsiva. O que o define é algo como o sentimento de onipotência quando ele é bem-sucedido e de impotência quando não o é. A culpabilidade que procedia de uma frustração implicava a elaboração de um projeto pessoal que, na modernidade, podia passar por muitos caminhos e se desdobrar em um dos campos em que uma compensação simbólica parecesse possível. Na posição de Dufour, o substituto do sentimento de culpa na pós-modernidade é a vergonha que exprime a intolerância narcísica à frustração e convoca uma remissão rápida. (Moreira \& Rosário, 2012, p. 82)

Melman (2003) aborda esta nova economia psíquica ligada ao neoliberalismo em que não domina o pacto de solidariedade, mas a concorrência e a agressividade. Para ele, "a identidade era organizada outrora a partir de um reconhecimento de si pelo Outro" (p. 172). A questão é que esse reconhecimento se organiza, hoje, a partir de um regime de visibilidade no qual só aparece como válido e vivo quem caminha nas trilhas do sucesso do Eu S/A, ou seja, o sujeito que se vê como uma miniempresa, como um miniempreendedor de sucesso, um sujeito que se autoproduz a partir das modalizações dos tecnólogos de discursos e que rala para não ser extinto pelos paredões do processo competitivo. Para Melman (2003):

Até aqui éramos sensíveis a uma clínica organizada pelo recalque. É através dela que a psicanálise veio à luz quando, continuando Freud, se aceitou ouvir os "ruídos" que os suspiros do desejo sufocado vinham fazer no campo da realidade. Passamos deste regime a um outro, no qual não apenas o desejo não é mais recalcado, mas em que são as manifestações do gozo que dominam. A participação na vida da sociedade, o laço social não passa mais pelo compartilhar um recalque coletivo, $\mathrm{o}$ que chamamos os usos e os costumes, mas, ao contrário, por uma reunião numa espécie de festa permanente para a qual cada um é convidado. O que hoje é encargo do sujeito é se manter na corrida pelo gozo. (p. 172-173)

Mas essa corrida produz uma dissociação ligada à fantasia e ao fetiche. Para Dunker (2017):

A chave para entender esse tipo de perversão ordinária está na dissociação e simplificação produzidas pela montagem da fantasia. Dissociação e simplificação encontradas na principal expressão sintomática da perversão, a saber, o fetiche, ou seja, esta propriedade ou esta função que permite transformar o outro em objeto inanimado (meio de gozo para meus fins) e reversamente o objeto em outro 


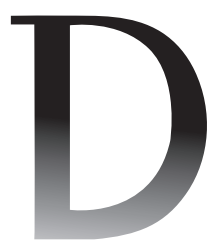

${ }^{4}$ Viana (2012) cita a fala "Pede pra sair", do filme Tropa de elite, em que o capitão do Bope (Batalhão de Operações Policiais Especiais), ao longo de uma seleção de admissão, esbofeteia os aspirantes e os obriga a realizar provas dolorosas. Diz Viana: "Como não podia deixar de ser, o filme se tornou mote de um dos espaços privilegiados de mobilização disciplinadora da força de trabalho, as palestras motivacionais. O ex-capitão do Bope, Paulo Storani, late para a plateia composta de executivos de uma grande seguradora: 'Você é um operação especial ou é um convencional na sua atividade? O convencional é o invertebrado, é quem desmonta no primeiro tiro ou na primeira meta.' Seu ponto final, 'E quem não está satisfeito...,' é completado pela plateia: 'pede pra sair"' (p.162).

animado (fim para o qual todos os meios o justificam). Em acordo com a regra perversa da inversão, o fetiche é a condição básica a que todo objeto deve atender para se tornar viável no universo de consumo. Para funcionar como tal, ele deve conseguir dissociar seu potencial de ilusão, de um lado, de seu efeito de decepção, do outro. Não é um acaso que Marx tenha descrito a economia capitalista baseando-se no fetiche da mercadoria. (p. 234)

Sem esses efeitos de ilusão e decepção, não se pode entender o funcionamento atual da cultura do consumo. Com a mercadoria de si mesmo, o empreendedor deve passar de invertebrado ${ }^{4}$ descapitalizado a empreendedor brilhante que escapa do paredão, conquista a plateia e busca o pódio de visibilidade dos VIPs.

\section{DE PASCAL A SADE}

Retomemos a trajetória de Dany-Robert Dufour para situar melhor a questão da perversão comum. Para Dufour (2013), o que se construiu no caminho que vai de Pascal a Sade, passando por Mandeville e Adam Smith, é a liberação das paixões e pulsões. Sem a reabilitação do egoísmo, não teria se constituído a cultura do consumo como a conhecemos hoje. A psicanálise é fundamental para se pensar uma teoria das paixões que dê conta dos afetos na operação da cultura do consumo. Esta montagem trata de liberar o sujeito consumidor egoísta e submetido ao supereu e à consciência moral e atirá-lo no mundo do sensível e da pulsão, fazendo adormecer o neurótico e eriçando a pelagem da montagem perversa. Isso não significa que o puritano tenha evaporado do mundo, pois o imperativo do gozo atual é ser perverso, realizar "as experiências mais radicais possíveis e, sobretudo, continuar clean" (p. 380). Este trânsito é apoiado com dança e batida musical de rave, com uso de entorpecentes e outras substâncias. Há uma série de saberes e de objetos ao redor dessa dança gozante.

Esta figura, ao mesmo tempo perversa e clean, é o perverso comum de Lebrun, o perverso puritano de que fala Dufour ou o perverso ordinário de Dunker. Propomos, aqui, entender a montagem perversa não como uma casa de suplícios, mas como um horizonte de competição agressiva, um campo minado no qual o eu empreendedor tem de se superar para derrotar os demais. Tal montagem é, portanto, um background de sustentação cultural em que o sujeito é motivado a se construir como um empreendedor de si, ou seja, que produza sempre mais e goze sempre mais, como dizíamos anteriormente a partir de Dardot e Laval (2016, p. 356): "esse é o duplo sentido de um discurso que faz do bom desempenho um dever e de um discurso publicitário que faz do gozo um imperativo". 
Não se busca o equilíbrio, mas o desempenho máximo, de campeão, visando ao pódio, ao gozo máximo, tanto na empresa como na rave: "Daí o interesse da identificação do sujeito como empresa de si mesmo e capital humano: a extração de um mais-de-gozar, tirado de si mesmo, do prazer de viver, do simples fato de viver, é que faz funcionar o novo sujeito e o novo sistema de concorrência" (p. 356). A subjetivação se dá, portanto, pelo excesso de si, tanto na empresa, quanto na rave, mesmo lá onde o sujeito esvanece. Pois ele se dissipa, mas volta mais carregado de gozo para retomar o empreendimento de si - a não ser que se deprima e se aceite invertebrado. Dardot e Laval (2016, p. 357) falam de ultrassubjetivação

cujo objetivo não é um estado último e estável de posse de si, mas um além de si sempre repelido e, além do mais, constitucionalmente ordenado, em seu próprio regime, segundo a lógica da empresa e, para além, segundo o 'cosmo' do mercado mundial.

De várias formas, o mercado produz espaços condominiais com circuitos perversos - em cinquenta tons de cinza e, eventualmente, com bilhões de cores - para os neuróticos mergulharem nele softly, mas intensamente, após as horas de trabalho e mesmo durante o dia de labuta. Algumas vezes, ele pode desejar um chicotinho ou algo mais picante, ao som da rave. Entretenimento é isso: mergulho no sensível, congelamento do inteligível, tanto nas raves quanto no cinema 4D, nas arenas esportivas, nas casas de swing, nos games e na realidade virtual e, até mesmo, nas experiências de marketing. Mas não só. Dentro do trabalho, ganhar dos adversários no cassino de apostas também é teste de desempenho e gozo 5 .

Nas raves, o uso de substâncias químicas facilita a passagem para o circuito perverso. Diz Dufour (2013, p. 369):

A mistura explosiva (droga mais "tum-tum") serve - literalmente - para "rasgar" a cabeça ou estourar a cabeça e ter acesso ao gozo - e devemos assim tomar essas expressões (criadas pelos amantes de techno e das raves para, em seguida, se disseminarem amplamente entre os jovens) ao pé da letra, já que se trata de lançar pelos ares um lugar de onde talvez pudesse provir um julgamento destinado a manter o corpo dentro de certas regras.

Como diz Fontenelle (2017, p. 191), é através da economia libidinal que "a economia mercantil e a economia psíquica convergem”. Por isso, não devemos separar o momento do trabalho concentrado do momento de entretenimento
${ }^{5}$ É preciso salientar que o marketing da experiência (Fontenelle, 2004) também atua de forma a construir espaços programados de consumo em que a convocação provoca o consumidor a viver uma experiência com cheiros, cores e imagens psicodélicas. 
gozante. Um é suplemento do outro. Sem a liberação das pulsões, a cultura do consumo não teria se desenvolvido no século XX: "embora o gozo no consumo já estivesse contido na cultura do consumo desde sua formação, essa paixão/ pulsão, que levada às últimas consequências é destrutiva, pôde ser contida por um preceito cultural do adiamento da satisfação como virtude" (p. 195). Mas hoje não mais.

Não há como manter o consumidor satisfeito, pois, para o capitalismo, é preciso que ele esteja em um estado constante de desejo, chegando até a beira de sua realização, mas recuando sempre, de modo a mantê-lo a todo o tempo desejando, mas permanentemente insatisfeito. Se ele se satisfaz, esta experiência é ligeira e aponta para uma satisfação maior e mais completa, construída imaginariamente pela cultura do consumo e transferida para o futuro. O circuito pulsional é ativado e reativado sem cessar para manter o consumidor sempre dirigido a essa satisfação maior, projetada no horizonte como promessa.

\section{A NOVA RAZÃO-QUADRO}

A nova razão do mundo, ou seja, o neoliberalismo, transforma as relações sociais, o Estado e a subjetividade. A razão neoliberal não é somente econômica, mas política e cultural. Isso envolve, segundo Dardot e Laval (2016), um sistema de normas elementares, com:

1. Uma norma transversal universal que oferece modos de relação de uns com outros. Devemos viver apostando na construção de nosso capital do eu em nossa imagem; isso, mais cedo ou mais tarde, desemboca numa experiência perversa;

2. A imposição de um modelo de empreendimento a partir do funcionamento das empresas, como se fôssemos microempresas dedicadas a nossa autocapitalização (p. 144 e 333).

O que está em vigência, ao fim e ao cabo, é o modelo concorrencial, a competição tal qual no esporte e nos realities. A razão do capital se amplia, portanto, a outras esferas, para além da estritamente econômica. Como consequência, tais modelos passam a regular esferas como amor e amizade - é o caso dos aplicativos de encontros, cada corpo se oferecendo como um perfil-produto e experimentando o maior número possível de posições e parceiros (Prado, 2015a). O próprio Estado se transforma em estado-empresa para apoiar os mercados, desativando a cidadania. O empreendedorismo se converte em modo de governo 
de si e o empreendedor especula, misturando risco e previsão e tentando prever acontecimentos incertos. Com isso, o homo economicus se torna mais dinâmico e mais dedicado ao corpo do que no passado, para a luta concorrencial. Quem perde, cai fora, se torna invisível, invertebrado, simbolicamente morto.

Entre as características da razão neoliberal, Dardot e Laval (2016, p. 377) colocam:

1. O mercado não é natural, mas construído, requerendo intervenção do Estado. A essência aí não está na troca, mas na concorrência.

2. O Estado não é só um vigilante, um guardião da ordem-quadro do neoliberalismo que instaura tal racionalidade e concorrência. É, mais que isso, um ativador e parceiro do mercado. Ele é o Estado-empresa, um dos garantidores e primeiros escorvadores dos grandes empreendimentos (megaprojetos) do capital na destruição de grandes parcelas de solo a fim de construir longos trechos de enormes edifícios a partir de uma lógica de financeirização na reurbanização do espaço, como o que ocorreu na Berrini em São Paulo, com substancial comparecimento dos capitais de fundos mútuos e de pensão.

3. A generalização da norma de concorrência atinge até os indivíduos em sua relação consigo. A empresa tornou-se modelo de subjetivação.

4. Desaparece a fronteira entre esfera privada e pública, corroendo os fundamentos da democracia liberal. Segundo esses autores, a racionalidade neoliberal adaptou-se ao que restou desta distinção no plano da ideologia, ao mesmo tempo em que desativou seu caráter normativo. Tal desativação introduz o caráter perverso no funcionamento institucional e subjetivo e tem como consequências: a diluição do direito público; a redução da ação pública aos critérios de rentabilidade e produtividade; a depreciação simbólica da lei como ato próprio do legislativo; a tendência dos poderes policiais de se isentarem do controle judicial; a promoção do cidadão-consumidor encarregado de arbitrar entre ofertas políticas concorrentes etc. (Dardot \& Laval, 2016, p. 379)

A cidadania passa, portanto, a ser questionada nas esferas sociais em que há pesada polarização política (Cf. Prado, 2018), colocando-se a aposta de que não pode haver mais direitos sem contrapartidas. $\mathrm{O}$ cidadão investido de 


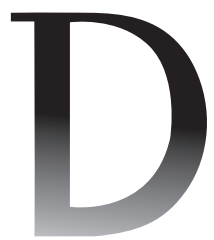

${ }^{6}$ Sobre a polarização durante o impeachment, cf. Prado, 2016b, 2018; Prado \& Prates, 2017a, 2017b, 2019. responsabilidade coletiva e de direitos desaparece e dá lugar ao empreendedor perverso clean. Dardot e Laval (2016) chamam este processo de reforma gerencial da ação pública. Ela vai contra a lógica democrática da cidadania, reforça a desigualdade social na distribuição dos auxílios e no acesso a emprego, saúde e educação e reforça as lógicas de exclusão que criam um número crescente de subcidadãos.

Para a instauração dessa nova racionalidade neoliberal, vimos que foi necessária a liberação das pulsões, que promoveu seus próprios critérios de validação de modo desconectado dos princípios morais e jurídicos da democracia liberal. Trata-se agora de uma razão gerencial para a qual leis e normas são apenas instrumentos que valem para se atingir objetivos calculados, havendo uma dessimbolização, a qual afeta a política e a subjetivação (Dardot \& Laval, 2016, p. 368).

A polarização política entre grupos que defendem a democracia e outros adeptos a valores e ao modo de vida neoliberal e/ou valores fundamentalistas, instaurada no Brasil a partir de 2015 e que acabou por desembocar no impeachment da presidente da República, se liga a esse processo de dessimbolização ${ }^{6}$. O perverso puritano, comum, ordinário ou clean é a figura desse autoempreendedor pós-cidadão que joga no lixo os princípios da democracia liberal, vestindo a bandeira verde-amarela.

\section{BATIDAS PULSIONAIS}

A tese de Dufour (2013) é que a música pode ser pornográfica: tanto a techno-rave das jovens classes médias e o gangsta rap dos jovens pobres são equivalentes, deste ponto de vista. "Elas servem para que os sujeitos fabriquem para si mesmos, por um lapso de tempo, um corpo pornográfico" (p. 370). Esta pulsação "massacrante" atua nos corpos antes que o sujeito dê seu consentimento. De alguma forma o sujeito morre para si mesmo para poder gozar, diz Dufour (2013, p. 372), transformando-se num autômato sexual. Uma série de substâncias pode ajudar neste processo de liberação e rebaixamento do inteligível e do moralizante, a fim de implantar um regime de pulsões livres. Isso é homólogo ao que ocorre com o mercado, o qual exige cada vez mais a "liberação e a exploração industrial das pulsões" (p. 375). O mercado pornográfico oferece condições para cada consumidor montar seu corpo pornográfico para quando o sujeito se esvair e o corpo pular na piscina perversa.

Assim, com a crescente liberação das pulsões, cresceu também o mercado pornográfico e estabeleceu-se uma ligação entre o neurótico consumidor e o perverso (menos ou mais puritano). O gozo buscado pelo consumidor neurótico 
é, portanto, o do perverso, em que se esvai o sujeito, exigindo para esse processo, como diz Dufour (2013), tais batidas musicais pulsionais fortes e substâncias variadas para entorpecer o argumento e liberar a sensibilidade na busca do gozo. Mas não são dois polos isolados, o neurótico e o perverso clean. Um suplementa o outro, como dissemos.

Haveria aí algo como uma oscilação entre graus de gozo. De um lado, teríamos o neurótico clássico, ainda submetido ao sentimento de culpa e, do outro, o neurótico mergulhado na montagem perversa (o perverso clean ou puritano de Dufour). A rigor, há uma passagem de um a outro extremo, em que vai gradualmente desaparecendo o sujeito, de modo a se intensificarem as sensações no corpo sensível, liberando sua potência de gozo na promessa imaginária de um gozo total, pleno. O corpo vai mergulhando no horizonte tensivo (Cf. Zilberberg, 2011) da perversão e deixando esfriar o sujeito até congelá-lo, enquanto o corpo aquece e se atira nas sensações e no gozo. É preciso salientar que essa passagem entre extremos não se dá somente na rave, mas também na empresa, quando trabalhar é uma guerra pela vitória. Nos filmes sobre Wall Street isto fica muito claro: a intensidade dos jogos de apostas no cassino mundial é um jorro de gozo, tanto quanto as noitadas nos prostíbulos de luxo em que os apostadores da "Rua do Muro" mergulham.

O mundo do consumo convida, portanto, os consumidores a se tornarem perversos clean e a retornarem para sua vida normal neurótica após as experiências sensíveis liberalizantes. De qualquer forma, não é uma divisão como em dr. Jekyl e Mr. Hide, pois aqui a montagem perversa é um substrato sensível no qual um objeto imaginário tampona o furo da castração simbólica, fazendo a lei (a linguagem, o simbólico) ser colocada entre parênteses para podermos gozar no topo ou olhar imaginariamente para o topo - pelo menos até a audiência (seja a dos realities ou a dos amigos do Facebook) nos atirar no paredão e nos transformar em invertebrados. Há aqueles que não conseguem voltar do topo e se viciam nas drogas, no sexo, no som alto, nas experiências de dor; os que simplesmente desistem; e os que se deprimem.

O resultado disso é uma sociedade na qual todos interiorizam a lei de mercado a fim de buscar a satisfação das pulsões, desligando, sempre que possível, a função sujeito, que se torna uma função evanescente, chamada quando o mundo social solicita; quando o discurso e as circunstâncias a convocam; ou quando o partido da justiça resolve encarcerar alguém indesejado para o sistema empreendedor.

Quando o sujeito é desligado, ou seja, quando se dá uma passagem ocasional para a perversão, emerge o substrato do perverso puritano, em que a face somática da pulsão se autonomiza. Este certamente não é um mundo feliz, 
${ }^{7}$ Uma leitura de Moreira e Rosário (2012), já citadas, poderia induzir a isso. Neste sentido, o alerta de Dardot e Laval (2016) é relevante. apesar das convocações, das promessas e das incitações. O consumidor busca o gozo, mas acaba eventualmente por sentir o desamparo e a falta de referências (Dufour, 2013, p. 173). Daí o sistema não é tão líquido quanto se anunciava na superfície publicitária, oferecendo a clínica, a medicalização ou a prisão.

Dardot e Laval (2016) afirmam que esta oscilação do neossujeito (o empreendedor neoliberal de si) "entre depressão e perversão" (p. 374) pode nos levar a uma apresentação cansativa e tal apresentação

que se faz entre um "individualismo hedonista" ou de um "narcisismo de massa" aparece como modo disfarçado de apelar para a restauração das formas tradicionais da autoridade. Ora, é um equívoco considerar o neossujeito à maneira dos conservadores. Ele não é em absoluto o homem do gozo anárquico "que não respeita mais nada". É um equívoco equivalente simétrico denunciar apenas a reificação mercantil, a alienação do consumo de massa. Obviamente a injunção publicitária ao gozo faz parte desse universo de objetos eletivos que, pela estetização-erotização da "coisa" e pela magia da marca, constituem-se em "objetos de desejo" e promessas de gozo. Mas também convém considerar a maneira como esse neossujeito, longe de ter deixado unicamente a seus caprichos, é governado no dispositivo de desempenho/gozo. (Dardot \& Laval, 2016, p. 374)

Não se deve permanecer atirando pedras no narcisismo e tendo ataques nostálgicos diante da perda da função paterna ${ }^{7}$. De acordo com Dardot e Laval (2016), o que se deve examinar com cuidado é:

- Avigilância do espaço público e privado;

- A rastreabilidade dos movimentos na internet;

- A avaliação minuciosa e mesquinha das atividades dos indivíduos;

- A ação cada vez mais pregnante dos sistemas conjuntos de informação e publicidade;

- As formas de autocontrole dos próprios sujeitos.

Como dizem esses autores, pode parecer que hoje nada mais "segura" o sujeito e o que falta é a força da autoridade. É inútil

lamentar a crise das instituições de enquadramento, como família, escola, organizações sindicais ou políticas, ou chorar a decadência da cultura e do saber ou o declínio da vida democrática. É melhor tentar compreender como todas essas instituições, valores e atividades são hoje incorporados e transformados no dispositivo desempenho/gozo, em nome de sua necessária "modernização"; é melhor examinar 
de perto todas as tecnologias de controle e vigilância de indivíduos e populações, sua medicalização, o fichar, o registro de seus comportamentos, inclusive os mais precoces; é melhor analisar como disciplinas médicas e psicológicas se articulam com o discurso econômico e com o discurso sobre segurança pública para reforçar os instrumentos da gestão social. (Dardot \& Laval, 2016, p. 375)

\section{SATISFAÇÃO E ESPAÇO DO COMUM}

A questão que se coloca aqui é: como poderá, este sujeito isolado que perde o contato com o coletivo, se responsabilizar por seu gozo? Ou, dito de outra forma, como pensar uma sociedade em que esta montagem perversa isola os sujeitos em busca de seu gozo? Ela não tende a se desintegrar? Os consumidores mergulhados em gozo só se relacionam com seus compadres de condomínio. Como podem dar o salto para o coletivo? Como criar o comum, a comunidade por vir? Essa é nossa atual questão política, por excelência. Estamos num cul-de-sac:

Tudo depende do que a sociedade tiver exigido e obtido dos futuros sujeitos: não há meio de esperar produzir sujeitos capazes de discernir o que continuam a dever ao coletivo sem que tenham sido antes de mais nada introduzidos por este mesmo coletivo nas exigências da condição humana (Lebrun, 2008, pp. 349-350).

Sob esta perspectiva, a tecnologia também é apresentada como campo de produção de gadgets mágicos capazes de transformar as relações entre pessoas de modo positivo, construindo uma imagem das redes como uma promessa de um futuro pensado como paraíso dos empreendedores de sucesso. Nestes contratos de comunicação da cultura do consumo, os enunciadores projetam um futuro, mas tornam invisíveis outras possibilidades. Os sentidos da tecnologia são disputados por vários setores nas sociedades e esses paraísos imaginários ligados a mundos do gozo, os quais, saturados de tecnologia, não consideram uma visão menos mercadológica do futuro, mais voltada para projetos sociais e compartilhados. Por essa razão, dizem Prado e Cazeloto (como citado em Prado \& Prates, 2017a, p. 126):

a colonização do futuro é uma estratégia discursiva que restringe as possibilidades das escolhas presentes pela apresentação do devir como direção unívoca, como se o futuro estivesse, desde sempre, inscrito no presente. Nessa estratégia, a crença na ausência de alternativas produz conformismo. Portanto, é tarefa central para a crítica social a desmistificação dos futuros imaginários unívocos e da afirmação de sua imponderabilidade determinista. 
${ }^{8}$ No original: "In every case the future embodies a type of satisfaction foreclosed to the present and dependent on one's investment in the capitalist system. The promise ensures a sense of dissatisfaction with the present in relation to the future.

... The promise of the better future is the foundation of the capitalist structure, the basis of all three economic areas production, distribution and consumption. If we examine only the field of consumption, universal commodification seems to hold the key, whereas if we confine ourselves to the field of production, the imperative to accumulate appears foundational. In the field of distribution, it is the idea of speed: one must move commodities to market in the least amount of time possible. If we look at what these three fields have in common, however, the answer is the promise of the future. One buys the commodity to discover a potentially satisfying pleasure, one accumulates more capital to someday have enough, and one speeds up the distribution process to increase one's future profit".

${ }^{9}$ No original: "The revolutionary act is simply the recognition that capitalism already produces the satisfaction that it promises".

${ }^{10}$ No original: "not as a possibility on the horizon but as the implicit structure of the present".
A projeção de um presente impulsionando os corpos a mergulharem nas piscinas de gozo também se liga a esses futuros imaginários. Isso se complementa com uma tendência dos consumidores a permanecerem situados (sitiados) em condomínios específicos, preparando seus corpos para o gozo para se autoempreenderem e se autocapitalizarem. Este horizonte perverso se complementa com as visões de futuros tecnológicos carregados de gadgets mágicos.

Neste contexto discursivo e pulsional do capitalismo comunicacional, as fantasias ligadas ao consumo colocam o consumidor sempre como insatisfeito e a todo o momento o convocam a buscar novas satisfações. A estrutura desse discurso é a da promessa (McGowan, 2016). O indivíduo deve ser mantido em estado de constante desejo, nunca se satisfazendo e ficando, portanto, a satisfação projetada num futuro imaginário (a cidade sem fios toda interligada por redes, o homem-ciborgue de corpo perfeito, a vida eterna depois da morte) como promessa. Para McGowan (2016),

Em todos os casos o futuro encarna um tipo de satisfação barrada (foreclosed) para o presente e dependente do investimento de cada um no sistema capitalista. A promessa garante um sentido de insatisfação com o presente em relação ao futuro. ... A promessa de um futuro melhor é a fundação da estrutura capitalista, a base para as três áreas econômicas - produção, distribuição e consumo. Se examinarmos apenas o campo do consumo, a mercantilização (commodification) parece dar a chave, enquanto se nos confinamos ao campo da produção, o imperativo de acumular parece fundacional. No campo da distribuição, é a ideia de velocidade: deve-se movimentar mercadorias até o mercado no menor período de tempo possível. Se olhamos para o que esses três campos têm em comum, contudo, a resposta é a promessa do futuro. Alguém compra uma mercadoria para descobrir um prazer potencialmente satisfatório, alguém acumula capital para algum dia ter o suficiente e alguém acelera o processo de distribuição a fim de aumentar o lucro futuro $^{8}$. (p. 12, tradução nossa)

McGowan (2016) afirma ser justamente esse investimento na promessa o que devemos abandonar: "o ato revolucionário está simplesmente em reconhecer que o capitalismo já produz a satisfação que ele promete" (p. 13). O que isso significa? Para McGowan, trata-se de situar o futuro "não como possibilidade no horizonte, mas como a estrutura implícita do presente" 10 (p. 13). Daí a necessidade de uma crítica imanente. O futuro não deve ser aquele projetado como realizador de todas as nossas satisfações. Não devemos fazer investimento psíquico na promessa da mercadoria. Para esse autor, o capitalismo funciona porque provê satisfação para os consumidores, mas 
oculta, ao mesmo tempo, o reconhecimento dessa satisfação. É preciso romper com este circuito e reconhecer a satisfação que o capitalismo proporciona. Isso implica em investir nossos esforços a partir da descoberta freudiana do inconsciente, entendido a partir do texto Além do princípio do prazer, no qual Freud lida com o conceito de repetição. O sujeito tem satisfação ao repetir experiências que nem sempre lhe dão prazer. O inconsciente não é apenas aquele da repressão, que oculta ideias sexuais perturbadoras da consciência, mas impele o consumidor a agir de modos que subvertem seus interesses e sente satisfação nisso: tais atos produzem um objeto perdido para o sujeito desejar e gozar. A satisfação do sujeito é, portanto, inseparável da perda autodestrutiva. Para McGowan (2016), é a repetição que atua como barreira para um futuro melhor. Para ele, a tarefa política atual está em entender como o capitalismo nos protege do encontro com o público, da ausência de garantias, da infinitude, do amor e da abundância. Os consumidores estão apegados à sua insatisfação e isso os faz aderir ao capitalismo. Eles se veem como seres insatisfeitos, perseguindo a satisfação e, portanto, não reconhecem a satisfação que já encontraram. A crítica ao sistema deve começar daí, da satisfação já conseguida, com os pés fincados no presente. Só assim o sujeito para de acumular (produção) e acelerar (distribuição). Do contrário, essa repetição cumulativa e acelerada continua a servir de tamponamento (ou anteparo) para o sacrifício (de tempo, energia e liberdade) exigido pelo sistema. Não há satisfação sem relação com a perda. O capitalismo nos protege ocultando-a. A questão é que nenhum objeto do desejo, diz McGowan (2016), pode ocupar plenamente o lugar do objeto perdido. $\mathrm{O}$ funcionamento deste dispositivo de consumo nos faz confundir o objeto do desejo com o objeto perdido. Aí se põe a ilusão constitutiva da cultura de consumo. Sem enfrentar essa perda, mudando a lógica da acumulação para a lógica da satisfação - que exige a aceitação do fato de nossa relação com a perda do objeto -, não podemos sair desta armadilha.

\section{A TÍTULO DE CONCLUSÃO}

A cultura do consumo atual promete gozo sem limites. Ela convoca os consumidores para seus contratos de comunicação a partir de palavras de ordem que promovam a busca de sucesso, de dinheiro, de felicidade e de gozo. Para chegar a ele, o consumidor deve aderir às convocações midiáticas dos tecnólogos de discursos para se modalizar corretamente e adquirir saber, aprender a querer (gozar), entender o dever ser e poder fazer o que deve ser feito para gozar. É na construção do Eu S/A que se aposta. Esse Eu é egoísta e isolado, 
goza em condomínios específicos, zonas de free jouissance. É numa promessa de gozo que se denega a perda de gozo (a partir da castração simbólica). Falar do horizonte cultural do perverso clean que sustenta a atual cultura do consumo é encarar de frente esta denegação.

Não se trata, portanto, de falar em sociedade perversa como um destino ou um panorama de falta de saída dominado pelo narcisismo, mas de compreender as mudanças da atual cultura de consumo em relação ao período anterior da Modernidade, bem como localizar os traços gerais pelos quais a cultura de consumo atual lida com os antagonismos e com a sexualidade. Uma "acontecimentalização" da política exige sujeitos que se ponham de modo não reativo diante dos acontecimentos, que estejam abertos ao devir a partir da democratização do presente. $E$ isso exige deslocar a ênfase da promessa para a estrutura do presente, encarando o papel da perda na satisfação. Frente a isso, não se trata de salvar o simbólico (McGowan, 2016, p. 347), mas a possibilidade de instalá-lo diante da dessimbolização em curso. Na impossibilidade de instalá-lo, caímos na guerra civil imaginária: a polarização. Para sair disso, é preciso instaurar a política do comum, ou, como diz Lebrun (2008), uma nova articulação entre singular e coletivo, passando da lógica da acumulação para a lógica da satisfação em sua relação com a perda. $\mathbf{M}$

\section{REFERÊNCIAS}

Chemama, R. (1995). Dicionário de Psicanálise. Porto Alegre, RS: Larousse; Artes Médicas.

Dardot, P. \& Laval, C. (2016). A nova razão do mundo: Ensaio sobre a sociedade neoliberal. São Paulo, SP: Boitempo.

Dufour, D. R. (2013). A cidade perversa. Rio de Janeiro, RJ: Civilização Brasileira.

Dunker, C. I. L. (2017). Reinvenção da intimidade: Políticas do sofrimento cotidiano. São Paulo, SP: Ubu.

Fontenelle, I. (2004). Mídia, acesso e mercado da experiência. Contracampo, (10/11), 185-200. doi: 10.22409/contracampo.v0i10/11.537

Fontenelle, I. (2017). Cultura do consumo: Fundamentos e formas contemporâneas. São Paulo, SP: FGV.

Freire Filho, J. (Org.). (2010). Ser feliz hoje: Reflexões sobre o imperativo da felicidade. Rio de Janeiro, RJ: FGV.

Freire Filho, J. \& Pinto Coelho, M. G. (Org.). (2011). A promoção do capital humano. Porto Alegre, RS: Sulina.

Julien, P. (2003). Psicose, perversão, neurose: A leitura de Jacques Lacan. Rio de Janeiro, RJ: Cia de Freud. 
Lacan, J. (1985). O Seminário, livro 20: Mais, ainda. Rio de Janeiro, RJ: Zahar. Laplanche, J. \& Pontalis, J. B. (1992). Vocabulário de psicanálise. São Paulo, SP: Martins Fontes.

Lebrun, J. P. (2008). A perversão comum: Viver juntos sem Outro. Rio de Janeiro, RJ: Cia de Freud.

McGowan, T. (2016). Capitalism and desire: The psychic cost of free markets. New York, NY: Columbia University Press.

Melman, C. (2003). O homem sem gravidade: Gozar a qualquer preço. Rio de Janeiro, RJ: Cia de Freud.

Moreira, J. O. \& Rosário, A. B. (2012). Culpa e narcisismo na tragédia moderna. Analytica, 1(1), 73-89. Recuperado de https://bit.ly/2Z11cXG.

Pezzotti, R. (2018). Convocações midiáticas para uma biossociabilidade do consumo: Sentidos atribuídos ao corpo na corrida de obstáculos Bravus Race. (Dissertação de mestrado). Escola Superior de Propaganda e Marketing, São Paulo, SP.

Prado, J. L. A. (2008). A invenção do Mesmo e do Outro na mídia semanal [DVD]. São Paulo, SP: PUC-SP.

Prado, J. L. A. (2011). Regime de visibilidade em revistas [DVD]. São Paulo, SP: PUC-SP.

Prado, J. L. A. (2013). Convocações biopolíticas dos dispositivos comunicacionais. São Paulo, SP: Educ.

Prado, J. L. A. (2015a). Da convocação da alma gêmea ao acontecimento amoroso. In A. Pinheiro \& C. Salles, Jornalismo expandido: Práticas, sujeitos e relatos entrelaçados (pp. 127-145). São Paulo, SP: Intermeios.

Prado, J. L. A. (2015b). Comunicação como epistemologia do sul: Do reconhecimento à emergência do acontecimento. Matrizes, 9(2), 109-125. doi: 10.11606/issn.1982-8160.v9.i2p.109-125.

Prado, J. L. A. (2016a). Afetos em confronto: Quem vai para a rua? In Seminário Afetos. Rio de Janeiro, RJ.

Prado, J. L. A. (2016b). Comunicação e reinvenção acontecimental da política. In E. Jesus (Org.), Reinvenção comunicacional da política (pp. 15-30). Brasília, DF: Compós.

Prado, J. L. A. (2018). Polarização e insatisfação midiatizadas no capitalismo comunicacional: como manter a democracia. In Ciseco 2018, Jarapatinga, AL.

Prado, J. L. A. \& Cazeloto, E. As tecnologias digitais num futuro despotencializado. In Prado, J. L. A. \& Prates, V. (2017). Sintoma e fantasia no capitalismo comunicacional (pp. 105-129). São Paulo, SP: Estação das Letras e Cores.

Prado, J. L. A. \& Prates, V. (2017a). O significante "povo brasileiro" na crise política do impeachment de Dilma Rousseff. In Conferência Internacional Patologias e Disfunções da Democracia, Covilhã, PBB. 
Prado, J. L. A. \& Prates, V. (Org.). (2017b). Sintoma e fantasia no capitalismo comunicacional. São Paulo, SP: Estação das Letras e Cores.

Prado, J. L. A. \& Prates, V. (2019). O afastamento de Dilma Roussef: afetos e discursos em disputa na política. Famecos, (no prelo).

Viana, S. (2012). Rituais de sofrimento. São Paulo, SP: Boitempo.

Zilberberg, C. (2011). Elementos de semiótica tensiva. São Paulo, SP: Ateliê.

Artigo recebido em 10 de setembro de 2018 e aprovado em 09 de janeiro de 2019. 